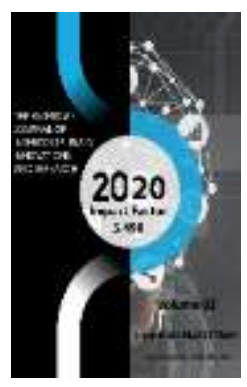

\title{
Developing Of Thinking And Creative Approach Towards Different Kinds Of Situations With The Help Of Solving Problems Of Mathematical Olympiads
}

\section{Sadullaeva Nodira Khujaboy Qizi}

The Student Of The Specialized IT School Named After Muhammad Al-Khwarizmi, Yashnabad, Tashkent, Uzbekistan

Journal Website: http://usajournalshub.c om/index,php/tajiir

Copyright: Original content from this work may be used under the terms of the creative commons attributes 4.0 licence.

\section{ABSTRACT}

The relevance of the article is due to insufficient knowledge of the problem of development of divergent thinking of student by means of the subject Olympiad. The meanings of the subject Olympiad of school students and the Olympiad movement of school students are explained. Also shown are approximate problems from real Olympiads with solutions.

\section{KEYWORDS}

Thinking, Olympiads, problems.

\section{INTRODUCTION}

In the modern world, there is a growing demand for an intellectual person who is able to think independently, set goals, formulate tasks, design ways to solve them, exercise selfcontrol and make adequate decisions.

\section{MATERIALS AND METHODS}

Encouraging basic school students to find solutions to various problems contributes to the development of divergent thinking.

In this article I present some problems from the International Formula of Unity / Third 
Millennium Olympiad, in which I myself directly participated and won prizes for several years in a row. Here are their different types with complete solutions.

\section{Problem \#1}

In a convex pentagon $A B C D E \angle A=60^{\circ}$, and other angles are equal to each other. It is known that $A B$ $=6, C D=4, E A=7$. Find the distance from point $A$ to the line $C D$.

\section{Solution:}

First, let's draw the figure. If we extend the sides of the pentagon, we get a triangle, which we denote as $\triangle F G H$. The sum of the interior angles of a pentagon $(n-2) \cdot 180^{\circ}=540^{\circ}$.

We find that all the interior angles of the pentagon are equal to $120^{\circ}$.

From this it follows that all the angles of the formed triangle are equal and it is equilateral.

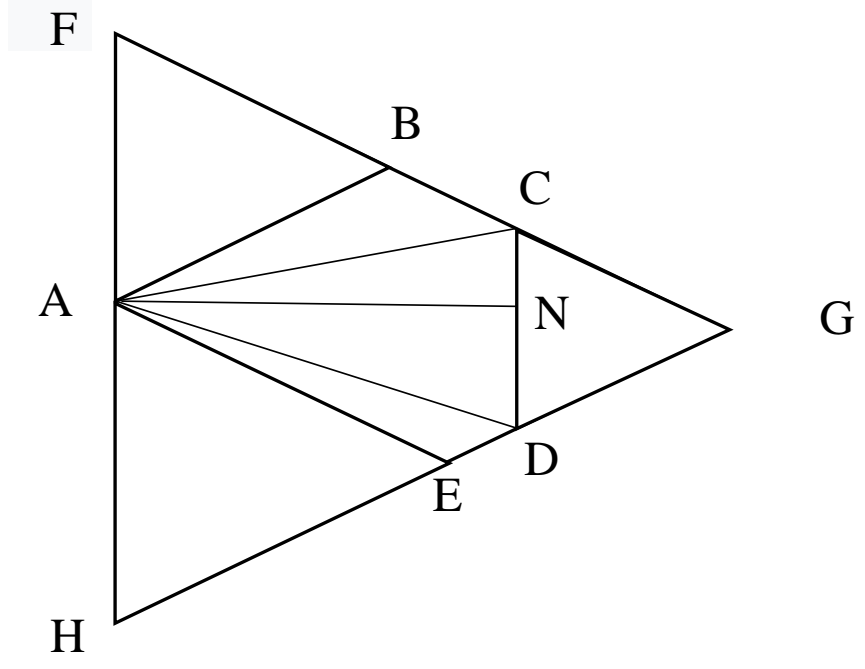

Wherein:

$A F=F B=A B=6$

$A H=A E=H E=7$

$C G=G D=C D=4$

$B C=6+7-6-4=3$

$E D=6+7-7-4=2$

Apply the cosine theorem for triangles $\triangle A B C$ and $\triangle A E D$ :

$A D=\sqrt{A D^{2}+E D^{2}-2 A E \cdot E D \cdot \cos \angle A E D}$

$A D=\sqrt{49+4+2 \cdot 7 \cdot 2 \cdot \frac{1}{2}}=\sqrt{67}$ 
$A C=\sqrt{36+9+2 \cdot 6 \cdot 3 \cdot \frac{1}{2}}=\sqrt{63}$

$A N \perp C D$

$A N=\frac{2}{C D} \cdot \sqrt{p(p-A C)(p-C D)(p-A D)}$

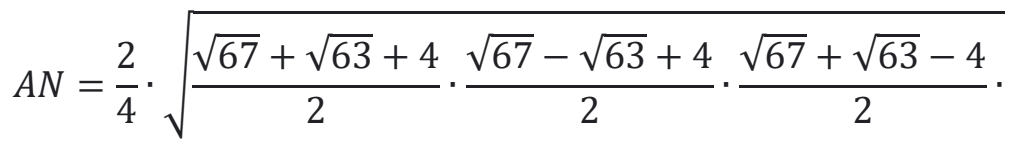

$\sqrt{\frac{-\sqrt{67}+\sqrt{63}+4}{2}}$

$A N=\frac{9 \sqrt{3}}{2}$

Answer: $\frac{9 \sqrt{3}}{2}$

\section{Problem \#2}

A positive integer $n$ is called cubic if $n^{3}+13 n-273$ is the cube of a natural number. Find the sum of all cubic numbers.

\section{Solution:}

If $0<13 n-273<3 n^{2}+3 n+1$, then $n$ cannot be cubic. These

inequalities are equivalent to $n>21$, so it remains to enumerate all the other numbers.

If $n=21$, then $13 n-273=0$, so 21 is cubic. For $n<21$, $13 n--273<0$, so for now $13 n-273>$ $-3 n^{2}+3 n-1$, the number $n$ will not be cubic (i.e. when $8<n<21$ ).

If $n=8$, then $13 n-273=-169=-3 \cdot 8^{2}+3 \cdot 8-1$, so it's cubic. For $n \leq 5$ expression $n^{3}+$ $13 n-273$ will be negative, so they're definitely not cubic. Numbers 6 and 7 are not cubic, you can check it directly.

The total answer is $8+21=29$.

Answer: 29 


\section{Problem \#3}

The pond is rectangular in shape. On the first frosty day, the whole part of the pond, from which to the nearest point of the shore no more than 10 meters, in the second - not more than $20 \mathrm{~m}$, on the third - no more than $30 \mathrm{~m}$, etc. For the first day, the area of open water decreased by $20.2 \%$, and for the latter - by $18.6 \%$ of the original area. Which one day will the pond freeze completely?

\section{Solution:}

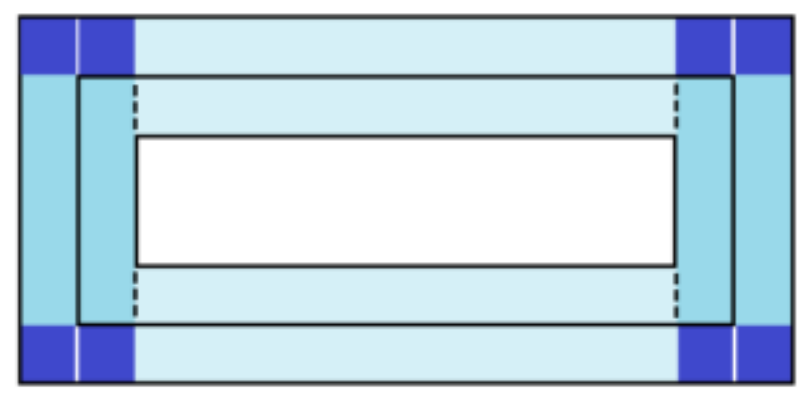

First way.

Let the sides of the pond be equal to $a$ and $b$ meters, then

$(a-20)(b-20)=(1-0.202) a b$,

$(a-40)(b-40)=(1-0.388) a b$,

whence $20(a+b)-400=0.202 a b, 40(a+$ b) $-1600=0.388 a b$,

that is, $800=0.016 a b, a b=5000$ and further $a+b=525$. It turns out that the sides are equal to 400 and 125 meters.

Second way.

Note that $800 \mathrm{~m}^{2}$ less freezing every day than the previous day. This can be seen from the figure, where it is shown that the "outer frame" consists of pieces, equal to the corresponding pieces of the "inner frame", and eight more squares $10 \times 10 \mathrm{~m}$.

This means that the percentage of the frozen part also decreases every day in the same way. That is, on the first day, $20.2 \%$ of the area was frozen, on the second $18.6 \%$, on the third $17.0 \%$ and etc. Note that the first six terms of this progression have a sum less than

$100 \%$, and the first seven members are already over $100 \%$. So, the pond will freeze on the seventh day.

Answer: on the seventh day

\section{Problem \#4}

Petya and Vasya are playing a game. They have a strip of 10 cells. On every move the player fits any number into any free cell. However, they do not take turns. First, Petya makes as many moves as he wants (but less than 10); then he asks Vasya make one move; after that Petya makes all the remaining moves. Petya will win if the resulting number turns out to be an exact square; otherwise Vasya wins. However, they believe that the number can begin with one or more zeros. Which player has a winning strategy?

\section{Solution:}

Petya has a winning strategy.

For example, this: he writes in the last two cells 04 . Note that if the number ends in 02 or 52 , then its square ends in 04 . Let us prove that for any Vasya's move Petya will be able to find an exact square.

Let Vasya rank among the hundreds. Consider the squares of numbers $2,52,102,152,202$, $252,302,352,402,452$. Find the difference between two adjacent squares:

$(50 a+2)^{2}=2500 a^{2}+200 a+4$, 
$(50 a+2)^{2}=2500 a^{2}+5200 a+2704$, whence $\quad(50 a+52)^{2}-(50 a+2)^{2}=$ $5000 a+2700 \equiv 700 \bmod 1000$.

Hence, the digit of hundreds of each next of these numbers is obtained from the previous an increase of 7 modulo 10 . Therefore, the hundreds in all these numbers are different $(0$, $7,4,1,8,5,2,9,6,3)$. Therefore, if Vasya goes into the category of hundreds, Petya will be able to complete the number to the square.

Let Vasya go to the category of thousands, that is, we have the number $* * * * * * x y 04$, where $x$ is given by Vasya.

Consider a series of numbers $(100 a+2)^{2}=$ $10000 a+400 a+4, a=0,2, \ldots 24$. In these numbers, $x y$ form an arithmetic progression with a difference of $4(04,08,12, \ldots, 96)$, so for each $x$ there is a suitable $y$.

If Vasya went to tens of thousands, then the reasoning is similar: among the squares 1|004|004, 4|008|004, 9|012|004, 16|016|004, 25|020|004, ..., 576|096|004 there are suitable ones.

If Vasya went into the category of hundreds of thousands or more, then such reasoning leads to considering too large numbers, but another idea works: let's try to do Vasya's digit is the first non-zero digit in our number.

Note that the squares of the adjacent numbers in the row $2,52, \ldots, 902,952$ differ less than per 100000 (this follows from the formula for the square of the sum), and $952^{2}>900000$, therefore the figure hundreds of thousands runs in them all values from 0 to 9 .

In a row 2, 52, ..., 2902, 2952, 3002 the squares of neighboring numbers differ by less than a million, and the latter exceeds 9 million; means that the figure of millions runs through everything values from 0 to 9 .
Let's consider the three most significant categories at the same time. In row $2,52, \ldots$, 99902, 99952 squares neighboring numbers differ by less than 10 million, and in the number $99952^{2}=9990402304$ all three most significant digits are nines. Hence, each of the three most significant digits runs through all values from 0 to 9 .

Answer: Petya

\section{RESULTS}

The development of divergent thinking of high school students, in our opinion, can be most effective in preparation for participation in subject Olympiads for schoolchildren.

\section{DISCUSSION}

Clarifying the essence of "subject Olympiads for schoolchildren", let us emphasize once again that their essence lies in the intellectual competitions of the "strongest".

\section{CONCLUSION}

Solving different kinds of problems, as well as from mathematical Olympiads has its positive impact on developing of thinking of schoolchildren.

\section{ACKNOWLEDGEMENTS}

Special acknowledgements for Sardor Bazarbaev Urinbaevich, chief specialist of the Ministry of Public Education of the Republic of Uzbekistan.

\section{REFERNCES}

1. Agaxanov N.X., Rubanov I.S., Podlipskiy O.K. “All-Russian Olympiads". Editor: Akimova T.Yu. Moscow: Prosvesheniye, 2013.

2. Levitas G.G. "Non-standard problems". Moscow: ILEKSA, 2009. 
3. Agaxanov N.X., Podlipskiy O.K. 'District Olympiads'. Moscow: Prosvesheniye, 2010.

4. Getmanova A. "Logic with problems". Moscow: Knorus, 2014.

5. Matyushkin M.A. "Thinking, education, creativity". Moskva: Izd-vo Moskovskogo psihologo-social'nogo in-ta. Voronezh: Izdatel'stvo NPO «MOD`EK», 2003. 